
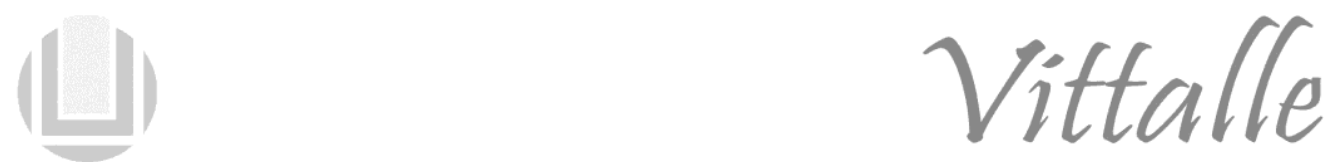

\title{
Aborto e microcefalia: inserção da bioética
}

\author{
Patrícia Martinez Echevenguá; Vanusa Belarmino*; Tatiane Nogueira Gonzalez; Maria \\ Carolina Maidana Vieira Piluski
}

Programa de Pós-Graduação em Ciências da Saúde, Faculdade de Medicina, Universidade Federal do Rio Grande FURG, Rio Grande, Rio Grande do Sul, Brasil.

Histórico do Artigo

Recebido em:

29/09/2016

Aceito em: 30/10/2017

Palavras-chave:

Aborto

Bioética

Microcefalia

Keywords:

Abortion

Bioethics

Microcephaly

\begin{abstract}
RESUMO
O presente estudo consiste em uma revisão integrativa de literatura com o objetivo de conhecer e analisar a produção científica sobre aborto no Brasil, microcefalia e Bioética, através da busca ativa de artigos científicos nas bases de dados Pubmed/Medline e Biblioteca Virtual de Saúde (BVS). A partir desta revisão, emergiram temas como: aborto legalizado, fetos anencéfalos, aborto induzido, questões conceituais sobre o aborto, humanização dos profissionais e microcefalia. Os artigos selecionados para a leitura foram apresentados em um quadro. Os temas selecionados foram categorizados da seguinte maneira: caracterização do sujeito $\mathrm{x}$ aborto induzido; dilemas bioéticos do aborto; aborto e a microcefalia e a percepção dos profissionais no aborto legal e humanização da prática do abortamento. Cabe ressaltar que discussão ainda é necessário, trazendo à tona a importância do tema para a saúde pública bem como a necessidade de definir políticas públicas que amparem essas mães envolvidas nesse contexto, independente de a causa ser o Zika vírus (ZIKV).
\end{abstract}

Abortion and microcephaly: insertion of bioethics

\begin{abstract}
This study consists of a literature integrative review aimed to know and analyze the scientific literature on abortion in Brazil, microcephaly and bioethics, through the active pursuit of scientific articles in the databases Pubmed / Medline and Virtual Health Library (BVS). From this review emerging issues such as legalized abortion, anencephalic fetuses, abortion, conceptual issues about abortion, humanization of professionals and microcephaly. The articles selected for reading were presented in a frame. The selected subjects were categorized as follows: characterization of the subject $\mathrm{x}$ induced abortion; bioethical dilemmas of abortion; abortion and microcephaly and the perception of professionals in the legal abortion and humanization of abortion practice. It notes that discussion is still needed, bringing to the fore the importance of the issue to public health and the need to define public policies that support these mothers involved in this context, regardless of the cause be the Zika virus (ZIKV).
\end{abstract}

\section{Introdução}

No ano de 2015, em Pernambuco, foi observado um aumento de casos de microcefalia quando comparados com uma série histórica de quatro anos. Diante da alteração do padrão de ocorrência de microcefalias no Brasil, o Ministério da Saúde notificou à Organização Mundial de Saúde (OMS) e declarou Emergência em Saúde Pública de Importância Nacional (ESPIN), em novembro de 2015. A OMS, em janeiro de 2016, fez o reconhecimento de haver relação do ZIKV com microcefalia e em fevereiro deste mesmo ano, declarou Emergência em Saúde Pública de Importância Internacional (1).

\footnotetext{
*Autor Correspondente: vanusa.cassino@gmail.com (V. Belarmino)
} 
Juntamente com o surto de microcefalia foi reaberto a discussão sobre a interrupção da gestação quando confirmado que as mães estão infectadas pelo ZIKV e os questionamentos Legalizar o aborto ou não? Aborto no caso microcefalia seria uma solução ou problema? Quem tem ou não tem direito a vida? Um surto de rubéola, na década de 70, fez com que houvesse um ferrenho debate em torno da liberação da prática para gestantes que contraíram a doença (2). No Brasil o aborto preventivo não é legalizado, no entanto, a lei brasileira permite o aborto em casos de risco à vida da gestante ou quando a gravidez é fruto de violência sexual. O Supremo Tribunal Federal, no ano de 2012, permitiu a interrupção da gravidez em casos de anencefalia, situação onde não ocorre a formação do cérebro no feto (3).

A descriminalização do aborto sempre foi um assunto polêmico, pois, existem duas correntes que se posicionam antagonicamente sobre o assunto.

Alguns grupos são a favor de políticas públicas que atendam ao desejo das mulheres de escolher pela gestação, evitando assim os abortos clandestinos que levam a consequências sérias como sequelas e mortes. Para esse grupo essa políticas tornariamse um benefício e ajudaria a salvar vidas.

Porém, existem outros grupos que discordam sobre a legalização e apoiam o direito à vida dos nascituros. Defendem que a legalização pode criar precedência para aborto em outras situações como a demência, a malformação congênita, a eutanásia e até mesmo em casos de coma prolongado. Especificamente em casos de microcefalia, essa corrente alega que o diagnóstico não se confirma na gestação, e essa criança teria a possibilidade de um desenvolvimento normal, tornando essa condição compatível com a vida.

Em torno dessas discussões polêmicas surge a necessidade de revermos, analisarmos e refletirmos sobre os princípios éticos. Dada à importância da defesa da vida e para orientar a tomada de decisão nessas situações faz-se necessário o uso dos princípios de não maleficência, de beneficência, de respeito à autonomia, da equidade e da justiça. Com isso o objetivo deste artigo é analisar os estudos sobre legalização do aborto e microcefalia sobre questões da Bioética. Para nortear a pesquisa formulou-se a seguinte questão: Qual a produção científica sobre legalização do aborto e microcefalia sobre as questões da Bioética?

\section{Materiais e métodos}

O presente estudo trata-se de uma revisão integrativa de literatura, por entender-se necessário analisar o que já foi escrito sobre a temática legalização do aborto, microcefalia e Bioética. Esse tipo de estudo tem como finalidade sintetizar resultados obtidos em pesquisas sobre um determinado tema, de maneira sistemática e ordenada, para contribuir com o conhecimento dessa temática (4).

Realizou-se pesquisa em duas bases de dados indexadas no mês de julho de 2016: Pubmed/Medline e Biblioteca Virtual de Saúde (BVS). Foram utilizadas palavras chaves e termos descritos pelo Medical Subject Headings (MeSH) e pelos Descritores em Ciências da Saúde (DeCS), os descritores utilizados foram: "abortion applicants" AND bioethics, os critérios utilizados para a seleção da amostra foram: artigos completos disponíveis eletronicamente, nos últimos cinco anos e os artigos que abordam as temáticas sobre legalização do aborto no Brasil, as referências obtidas foram importadas para o programa EndNote ${ }^{\circledR} \mathrm{X} 7$ gerando duas bibliotecas, uma para cada base de dados, na Pubmed com 111 artigos e BVS com 59 artigos. Essas bibliotecas foram cruzadas, totalizando 170 artigos. Em seguida foram excluídos:as 06 duplicatas. Ao final dessa etapa, restaram 164 artigos para leitura dos títulos. 
Após a leitura dos títulos, restaram 35 artigos que apresentaram relação com tema de estudo, em seguida, foi feita a leitura dos resumos. Para a revisão integrativa foram selecionados 9 artigos para serem lidos na íntegra e responderam a questão norteadora.

A essência da revisão integrativa é a categorização dos estudos. Neste sentido, procede-se a apresentação dos resultados e discussão das informações de forma descritiva e por meio de um quadro (Tabela 1) onde foram organizados os estudos segundo os itens: título, periódico/ano, objetivo e método.

Tabela 1 - Síntese dos estudos incluídos na revisão integrativa.

\begin{tabular}{|c|c|c|c|}
\hline & Título do estudo & Periódico/Ano & Objetivo e Método \\
\hline 1 & $\begin{array}{l}\text { Percepção de profissionais } \\
\text { da saúde sobre } \\
\text { abortamento legal }\end{array}$ & Revista Bioética, 2015 & $\begin{array}{l}\text { Objetivo: identificar o conhecimento e a } \\
\text { percepção dos aspectos éticos } \\
\text { envolvidos no programa de Interrupção } \\
\text { Gestacional Prevista em Lei, por parte } \\
\text { de profissionais de saúde do Hospital } \\
\text { materno Infantil de Brasília que não } \\
\text { lidam diretamente com os serviços de } \\
\text { abortamento legal dessa instituição. }\end{array}$ \\
\hline 2 & $\begin{array}{l}\text { Conscientious objection, } \\
\text { barriers, and abortion in the } \\
\text { case of rape: a study } \\
\text { among physicians in Brazil }\end{array}$ & $\begin{array}{l}\text { Reproductive Health } \\
\text { Matters, } 2014\end{array}$ & $\begin{array}{l}\text { Método: abordagem qualiquantitativo. } \\
\text { Objetivo: descrever } \\
\text { a opinião e conduta de ginecologistas e } \\
\text { obstetras brasileiros sobre o aborto em } \\
\text { caso de estupro. }\end{array}$ \\
\hline 3 & $\begin{array}{l}\text { Avaliação da atenção } \\
\text { humanizada ao } \\
\text { abortamento: um estudo de } \\
\text { avaliabilidade }\end{array}$ & $\begin{array}{l}\text { Revista de Saúde } \\
\text { Coletiva, } 2013\end{array}$ & $\begin{array}{l}\text { Método: abordagem qualiquantitativo.. } \\
\text { Objetivo: discutir se o conjunto de } \\
\text { intervenções, definidos na Norma } \\
\text { de Atenção Humanizada ao } \\
\text { Abortamento constitui um programa } \\
\text { avaliável em } \\
\text { uma maternidade-escola de referência do } \\
\text { SUS em Natal, RN. }\end{array}$ \\
\hline & & & $\begin{array}{l}\text { Método: abordagem qualitativa, de } \\
\text { análise documental e entrevista com } \\
\text { informantes-chave. }\end{array}$ \\
\hline 4 & $\begin{array}{l}\text { Moral consensus theory: } \\
\text { paradigm cases of abortion } \\
\text { and orthothanasia in Brazil }\end{array}$ & $\begin{array}{l}\text { Indian Journal of } \\
\text { Medical Ethics, } 2013\end{array}$ & $\begin{array}{l}\text { Objetivo: refletir sobre os aspectos } \\
\text { morais do aborto e da ortotanásia no } \\
\text { Brasil. }\end{array}$ \\
\hline & & & $\begin{array}{l}\text { Método: abordagem qualitativa, de } \\
\text { natureza conceitual. }\end{array}$ \\
\hline 5 & $\begin{array}{l}\text { Cenário de } \\
\text { desenvolvimento da vida } \\
\text { humana e reflexões sobre } \\
\text { aborto }\end{array}$ & Revista Bioética, 2012 & $\begin{array}{l}\text { Objetivo: classificar o processo de } \\
\text { criação do ser humano, e a sua análise } \\
\text { lógica. }\end{array}$ \\
\hline & & & $\begin{array}{l}\text { Método: abordagem qualitativa de cuho } \\
\text { exploratório. }\end{array}$ \\
\hline 6 & $\begin{array}{l}\text { Abortamento induzido: } \\
\text { vivência de mulheres } \\
\text { baianas }\end{array}$ & $\begin{array}{l}\text { Revista Saúde Sociedade } \\
\text { São Paulo, } 2012\end{array}$ & $\begin{array}{l}\text { Objetivo: identificar situações que } \\
\text { interferem na decisão pelo aborto e os } \\
\text { sentimentos diante do processo de } \\
\text { abortar. }\end{array}$ \\
\hline & & & $\begin{array}{l}\text { Método: abordagem qualitativa, de } \\
\text { cunho descritivo. }\end{array}$ \\
\hline 7 & $\begin{array}{l}\text { The fallacy of neutrality: } \\
\text { the interruption of }\end{array}$ & Bioethics, 2011 & $\begin{array}{l}\text { Objetivo: explorar os argumentos sobre } \\
\text { a interrupção da gravidez. }\end{array}$ \\
\hline
\end{tabular}


pregnancy of anencephalic fetus in Brazil

8

As mulheres brasileiras e o Revista Bioética, 2010

aborto: uma abordagem

Bioética na saúde pública

9

Abortamento provocado na adolescência sob a perspectiva Bioética
Revista Brasileira de Saúde Materno Infantil, 2016
Método: abordagem analítica.

Objetivo: refletir criticamente sobre a criminalização do aborto no Brasil.

Método: Revisão bibliográfica.

Objetivo: descrever características

sociodemográficas, comportamentais,

clínicas, anatomopatológicas e o tipo de abortamento em adolescentes. De modo a discuti-las Bioéticamente.

Método: estudo descritivo.

\section{Resultados}

\section{Caracterização dos estudos analisados}

Em relação à caracterização dos nove artigos selecionados, estes foram publicados no período de 2010 a 2016. Esses artigos apresentam abordagem qualitativa, sendo dois qualiquantitativos, um estudo de revisão de literatura, três estudos exploratórios descritivos, um estudo conceitual, um analítico e uma análise documental.

Os artigos que constituem a amostra do presente trabalho abordaram aspectos como: caracterização do sujeito que realiza aborto induzido, dilemas bioéticos do aborto, a incidência de microcefalia e o aborto e, por fim, a percepção dos profissionais no aborto legal e humanização, assim a discussão será apresentada de acordo com as categorias encontradas a partir da semelhança entre os temas.

\section{Discussão}

\section{Perfil das mulheres que realizam aborto induzido}

Essa categoria é composta com três artigos (listagem da tabela artigo 6, 8 e 9), que apresentam questões referentes à caracterização das mulheres que realizaram aborto induzido. Segundo registros do ano de 2010 do Sistema Único de Saúde, desde 2005, ocorrem 1,2 milhões de internações por complicações de abortos ilegais, em virtude da ilegalidade, é difícil de mensurar com fidedignidade desses resultados, e devido às complicações deste ato está entre as principais causas de mortalidade materna (5)

As maiores taxas de morbimortalidade por complicações pós-aborto ocorrem mais frequentemente nas mulheres das classes com menor poder socioeconômico, demonstrando que estas se submetem a métodos mais inseguros e precários. O perfil das mulheres que abortam em clínicas clandestinas é: idade entre 20 e 29 anos, baixa escolaridade, cor da pele negra, não casada, sem ou com poucos filhos (máximo de dois) $(5,6)$. Conforme estudo de Sandi, $12 \%$ das mulheres que realizam aborto já haviam feito antes, a maioria realizado entre seis e doze semanas de gravidez, não usavam métodos contraceptivos e a maior parte dos parceiros apoiaram ou não ficaram sabendo (5). Gestantes que realizaram a prática em unidades públicas possui perfil diferente, essas, em sua maioria, são casadas, estudaram por até oito anos, já têm filhos e são católicas, a idade não varia, neste grupo prevalencem mulheres entre 20 e 29 anos de idade (5)

Estudo realizado com adolescentes apresentou como perfil das gestantes que realizam aborto a idade média de 16,1 anos, cor da pele parda, parceiro estável. Quanto ao 
conhecimento da contracepção, 83,6 \% conheciam anticoncepcional oral e 91,2\% camisinha. Em relção à contracepção da gravidez atual, nenhuma das avaliadas citou uso de preservativo nas relações sexuais, $70,1 \%$ não usavam método contraceptivo no mês da gestação e $29,8 \%$ uso de algum método (7).

A motivação do aborto está relacionado a gestação indesejada, não planejamento, situação financeira, incentivo do companheiro, sentimento de abandono e desprezo, a violência do gênero, como violência doméstica, não só a violência física e psicológica, como violência sexual (estupro doméstico), e a dificuldade de acesso ao sistema de saúde são fatores que expõem a mulher ao dano acessório $(5,6,7)$.

\section{Dilemas éticos do aborto}

Esta categoria compõe-se por três artigos (listagem da tabela artigos 4,5 e 7) que explanam os dilemas morais da prática do aborto, assim como o processo de formação da vida humana.

O aborto é, dentre as situações analisadas pela Bioética, um assunto que ocasiona um acirrado e profuso debate. O surto de ZIKV, acompanhado pelos inúmeros casos de microcefalia, apenas reacendeu esta discussão. A Bioética não dita às regras das nossas ações, mas sim permite uma reflexão sobre os conflitos e dilemas morais que permeiam as questões da saúde e da vida. Segundo o autor, ela é vista como o exercício humanista de pensar sobre os conflitos naturais, e, mais ainda, visa combinar a biologia e os valores humanos de forma que os dilemas morais e éticos sejam tratados e seguidos de forma ética (8).

Cabe ressaltar que, os dilemas que envolvem esta problemática dificilmente são tratados apenas do ponto de vista da ciência, o tema envolve valores morais e sociais que dificultam e entravam a discussão, pois há correntes muito distintas ${ }^{5}$. De um lado, a dos defensores da não legalização da prática, com o argumento de que a gravidez é sagrada, fundamentados no princípio da sacralidade da vida. De outro, os que defendem que é necessário respeitar a autonomia da mulher, seu direito de tomar suas próprias decisões enquanto agente moral.

Possivelmente, o maior entrave destas duas correntes seja a falta de consenso sobre o entendimento de quando a vida começa. O cerne da questão, todavia, não há consenso no reconhecimento do momento em que a vida inicia $(5,7,8)$. A concepção do surgimento da vida varia de acordo com fundamentações cientificas, filosóficas e religiosas, igualmente, com as crenças e costumes dos povos. $\mathrm{O}$ autor menciona que, embora não haja unanimidade, há um conceito de começo de vida que se relaciona ao conceito de morte (9). Este consenso, instituído pela comunidade cientifica, estabelece que se a morte cerebral ou encefálica é a interrupção da vida, logo, o começo da vida igualmente se relacionaria com o começo da atividade encefálica. Ressalta-se que, uma das finalidades de conhecer o princípio da vida é a de lhe conferir direitos, dentre eles o direito a própria vida (9).

Enfim, independente do posicionamento, seja ele a favor ou contra a prática do aborto, e, enquanto a sociedade e a ciência não entram em um acordo, um fato é claro, os governos precisam esforçar-se em promover os direitos, o protagonismo social e a saúde das mulheres. Necessitam, por meio da educação, prevenir a gravidez indesejada e efetivar o planejamento familiar para que o abortamento não seja utilizado como um método contraceptivo (7). Além disso, independente de questões religiosas e politicas, o assunto deve ser sempre debatido pautando-se nos princípios que norteiam a Bioética: Autonomia, Beneficência, Não maleficência e Justiça. Pois, diante da impossibilidade 
da conduta humana sempre suceder o bem, a ocorrência de condutas e ações errôneas será menor (9).

\section{Microcefalia e o aborto}

Nessa categoria não foram encontrados estudos na busca.

Conhecida como uma mal formação congênita, na microcefalia, o cérebro não é desenvolvido satisfatóriamente.

O aborto, no Brasil, somente é permitido em três situações: a primeira em caso de estupro; a segunda quando o feto é diagnosticado com anencefalia, condição considerada incompatível com a vida e, a terceira quando existe risco de vida da mãe (3).

Em relação à microcefalia, são crianças comprovadamente com deficiências, uma vez que, essa malformação pode causar várias consequências e em diferentes níveis. Porém, essas crianças têm vida e o fato de apresentarem dificuldades de natureza mental ou física não torna essa vida com mais ou menos significância. Portanto, crianças que nasceram com microcefalia, independente da causa ser o ZIKV, não estão condenadas a morte. O que poderão é ter uma vida com menos autonomia, menos cidadania e muito restrita devido às barreiras sociais. Elas podem ser possíveis vítimas de duas deficiências: políticas sanitárias, que permitiram a proliferação do mosquito, e políticas de inclusão (10).

O principal argumento contra a interrupção terapêutica de uma gravidez de um feto anencefálico é para dizer que o procedimento é, na verdade, um tipo de aborto, que, por conseguinte, viola o feto direito à vida (11).

São elas, também, que encontram as maiores barreiras para criar um filho com deficiências, num governo que falha na garantia de acesso a tratamento de saúde e acesso pleno à cidadania. Portanto, é de extrema importância que ocorra a discussão sobre o aborto com a seriedade que merece por tratar-se de um problema de saúde pública.

Uma das complicações desse debate é que o tema aborto, para a sociedade brasileira, ainda é considerada um tabu.

\section{A percepção dos profissionais no aborto legal e humanização da prática do abortamento}

Esta categoria compõe-se por três artigos (listagem da tabela artigos 1, 2 e 3) que apresentam a percepção dos profissionais de saúde sobre o abortamento legal no Brasil, bem como práticas de humanização ao abortamento.

Um estudo realizado no Hospital Materno Infantil de Brasília analisou o conhecimento e a percepção dos aspectos éticos envolvidos no Programa de Interrupção Gestacional Prevista em Lei (12). Observou-se que questões de cunho ético, moral, religioso e cultural exercem forte influência sobre a percepção do tema pelos profissionais de saúde que lidam com o aborto. $\mathrm{O}$ estudo aponta como principal causa dessa problemática, a falta de divulgação associada ao estigma e ao preconceito presentes nessa temática, indicando a necessidade de capacitação ética contínua dos profissionais, como forma de qualificar o atendimento às mulheres que recorrem ao serviço de referência para interrupção de gravidez nos casos previstos em lei (12).

Um estudo realizado com o objetivo de analisar condutas entre ginecologistas e obstetras nos casos de aborto por estupro no Brasil, sugeriu que gestantes vítimas de estupro encontram dificuldades e barreiras por parte dos médicos para poderem ter suas gestações interrompidas. O estudo recomenda que o Ministério da Saúde e e os 
profissionais médicos trabalhem juntos, afim de que os médicos possam ter mais informações sobre esses casos estupropermitindo o acesso a um aborto legalizado (13).

Foi proposto um modelo de avaliação da Norma Técnica de Atenção Humanizada ao Abortamento do Ministério da Saúde, que serve como um guia para uma atenção pósabortamento de qualidade, além de ser um referencial ético e legal para os serviços e profissionais na assistência à saúde das mulheres (14). Ainda são poucas as investigações que avaliam especificamente a qualidade da atenção ao abortamento dentro dos marcos legal, ético e políticos da Norma da Atenção Humanizada ao Abortamento.

Um estudo de avaliabilidade é o primeiro passo para avaliar programas, aumentando a probabilidade de fornecer avaliações oportunas, relevantes e de interesse para as tomadas de decisão de saúde públicareferntes a saúde da mulher (15). A atenção humanizada ao abortamento é um programa avaliável com elaboração de um modelo de avaliação no momento oportuno. Entretanto, conclui-se que práticas de humanização no abortamento devem ser garantidas e praticadas por todos profissionais que atendem a mulher, evitando estigmas e permitindo uma atenção qualificada.

\section{Considerações Finais}

Apesar de muito debatido, ainda há entraves e barreiras morais e éticas que dificultam o avanço no consenso democrático e no conhecimento cientifico fundamento na adoção de medidas sobre o tema do aborto.

A contextualização e o conhecimento do perfil da mulher que realiza o aborto é fundamental para tentar solucionar a problemática. Cabe ressaltar que não haverá progresso sem que haja conhecimento da disparidade moral e cultural da população atingida.

Nossas políticas públicas são retrogradas e injustas. A busca pelo aborto, ocasionalmente, é gerada pela falta de orientação, apoio e de perspectiva de vida digna à gestante e a criança que está por vir. Independente do debate filosófico e moral, na clandestindidade, o aborto continua a acontecer, e enquanto não tratarmos as causas o problema não se resolverá.

\section{Referências}

1. Heukelbach J, Alencar C, Kelvin A, Oliveira W, Cavalcanti LPG. Zika virus outbreak in Brazil.The Journal of Infection in Developing Countries 2016; 10(02): 116-120.

2. Batista L. Microcefalia e aborto: debate não começou com Zika. Jornal O Estadão [Internet] 2016; 12064(0) - [citado em 2016 Ago 16]. Disponível em: http://acervo.estadao.com.br/noticias/acervo,microcefalia-e-aborto-debate-nao-comecou-comzika, 12064.0.htm

3. Brasil. Supremo Tribunal Federal. Informativo $n^{\circ}$ 661, de 9 a 13 de abril de 2012.[Internet]. Disponível em: http://www.stf.jus.br/arquivo/cms/noticianoticiastf/anexo/adpf54.pdf

4. Roman AR, Friedland, MR. Revisão integrativa de pesquisa aplicada à enfermagem. Cogitare Enfermagem 1998;3 (2):109-112.

5. Sandi SF, Braz M. As mulheres brasileiras e o aborto: uma aborfagem da Bioética na saúde pública. Revista Bioética 2010; 18 (1): 131-153.

6. Pereira VN, Gomes NP, Couto TM, Paixão GPN. Abortamento induzido: vivência de mulheres baianas. Saúde e Sociedade 2012; 21 (4):1056-1062.

7. Chaves JHB, Pessini L, Bezerra AFS, Rego G, Nunes R. Abortamento provocado na adolescência sob a perspectiva bioética. Revista Brasileira Saúde Materno Infantil 2010; 10 (2): 311-319. 
8. Miziara ID, Miziara CS. Moral consensus theory: paradigm cases of abortion and orthothanasia in Brazil. Indian Journal of Medicals Ethics 2013; 10 (1): 58-61.

9. Spiandorello WP. Cenário de desenvolvimento da vida humana e reflexes sobre o aborto. Revista Bioética 2012; 20 (3): 425-435.

10. El País. Sobre aborto, deficiência e limites. Comissão de Cidadania e Reprodução. [Internet] 2016 [citado em 2016 Ago 20]. Disponível em: http://www.ccr.org.br/noticiadetalhe.asp?cod=16841\#.WUdZu R IV

11. Fonseca ANC. The fallacy of neutrality: the interruption of pregnancy of anencephalic fetus in Brazil. Bioethics 2011; 25 (8): 458-462.

12. Rocha WB, Silva AC, Leite SML, Cunha T. Percepção de profissionais da saúde sobre abortamento legal. Revista Bioética 2015; 23 (2): 387-399.

13. Diniz D, Madeiro A, Rosas C. Conscientious objection, barriers, and abortion in the case of rape: a study among physicians in Brazil. Reproductive Health Matters 2014; 22 (43): 141-148.

15. Rocha BNGA, Uchoa SAC. Avaliação da atenção humanizada ao abortamento: um estudo de avaliabilidade. PhysissRevista de Saúde Coletiva 2013; 23 (1): 109-127. 